\title{
Diffuse Endobronchial Wall Spread of Metastatic Breast Cancer
}

\author{
Tomonobu Koizumi ${ }^{a} \quad$ Nobumitsu Kobayashi ${ }^{a}$ \\ Shintarou Kanda ${ }^{a}$ Masanori Yasuo ${ }^{a}$ Keishi Kubo ${ }^{a}$ \\ Kenichi Itou ${ }^{b}$
}

aFirst Department of Medicine and ${ }^{b} S e c o n d$ Department of Surgery, Shinshu

University School of Medicine, Matsumoto, Japan

\section{Key Words}

HER-2 - Vinorelbine · Trastuzumab · FDG-PET · Endobronchial metastasis

\begin{abstract}
We present here a case of diffuse tracheobronchial wall spread of metastatic breast cancer who was successfully treated with trastuzumab plus vinorelbine chemotherapy. The patient had a left radical mastectomy for breast cancer in March 2000 and developed persistent cough and dyspnea in November 2006. Pulmonary function test demonstrated an obstructive pattern. Chest computed tomography showed a wall thickening of trachea and right side bronchus, but radiographic findings including ${ }^{18} \mathrm{~F}$-fluorodeoxyglucose positron emission tomography failed to detect the locations of disease in the lung. The findings on bronchofiberscopy showed edematous tracheobronchial mucosa, but also failed to visually detect direct masses. Transbronchial biopsy specimens revealed involvement of metastatic breast cancer. The patient was treated with trastuzumab plus vinorelbine chemotherapy and the wall thickening of bronchial tree and clinical symptoms were improved. Although endobronchial metastasis in metastatic breast cancer is not uncommon, diffuse spread without forming intraluminal mass is extremely rare. The pattern of endobronchial metastasis should be considered in patients with malignancies even when radiographic abnormalities are undetectable.
\end{abstract}

\section{Introduction}

The lungs are often involved in extrapulmonary malignancies, but endotracheal/endobronchial metastases are uncommon [1-3]. The diagnosis is made by presence of bronchoscopically visible tumors on the bronchus and histological findings identical to primary tumors at another site [1-3]. The invasion of the endobronchial wall 
has been thought to be from parenchymal or mediastinal lymph node metastasis, and/or from both. In general, radiographic examinations of chest radiograph or computed tomography (CT) revealed the abnormal findings, such as atelectasis, hilar or mediastinal lymphadenopathy, intraluminal tumor or pulmonary nodules [1-4]. We encountered a case of diffuse tracheobronchial wall metastasis of breast cancer, in which radiograph and endoscopy failed to detect direct masses. The patient presented persistent cough, dyspnea and an obstructive pattern in pulmonary function test, which were indistinguishable from other pulmonary diseases. The rare manifestation as in this case is a pitfall in diagnosis and management in patients with breast cancer.

\section{Case Presentation}

A 54-year-old woman was admitted to our hospital in November 2006 because of cough and dyspnea on exertion. She had had a left radical mastectomy for breast cancer in March 2000. Postoperative radiation (54 Gy) was administered because of histological evidences of metastasis in axillary lymph nodes. The patient was initially referred to our hospital in October 2002 because of an abnormal finding on chest radiograph during follow-up. She was asymptomatic and a $20-\mathrm{mm}$ nodule was observed in the right S2 without any hilar or mediastinal lymphadenopathy. Bronchoscopic examination did not show any abnormalities on the proximal bronchus, but revealed malignant cells (adenocarcinoma) from the nodule. Right upper lobectomy was performed and the histological findings confirmed metastatic breast cancer. The resection margin was free from tumor involvement and there were no abnormal findings on other radiographic examinations, including bone scan, brain and abdominal CT. The immunohistochemical examination revealed human epidermal growth factor receptor-2 (HER-2) overexpression and was negative for estrogen receptor and progesterone receptor. Postoperative adjuvant chemotherapy was performed with 6 cycles of epirubicin plus cyclophosphamide chemotherapy and followed by trastuzumab plus paclitaxel therapy until October 2004. There were no clinical signs of relapsing breast cancer including radiographic findings and increases in specific tumor makers.

However, the patient presented persistent cough and developed exertional dyspnea in November 2006. Pulmonary function test showed an obstructive pattern (forced expiratory volume in $1 \mathrm{~s}\left(\mathrm{FEV}_{1}\right)$, 1.381 and $59.2 \%$ of predicted). Physical and laboratory examination identified no abnormal findings (chest CT scan at the time is shown in fig. 1). The thickened wall in trachea and right bronchus were observed, but no abnormal masses were detected in both lungs and mediastinum. ${ }^{18} \mathrm{~F}$ fluorodeoxyglucose positron emission tomography (FDG-PET) showed a weak accumulation of right hilar lesions, but no abnormal findings in the lung and other organs (igg. 2). These findings were inadequate for diagnostic criteria in the presence of abnormality on chest CT and FDG-PET. Since her symptoms persisted, a flexible bronchoscopy was performed. The bronchoscopic findings revealed edematous mucosa throughout the tracheobronchial tree without any elevated lesions suggesting a malignancy (fig. 3 ). Since brushing cytology revealed a presence of malignant cells (adenocarcinoma), subsequently transbronchial core needle biopsy from the spar between middle and basal bronchus was performed. The histological diagnosis of metastatic lung tumor was obtained and immunohistochemical examination revealed the same pattern as that in previously excised lung tumor (HER-2 (+++), ER (-) and PR (-); fig. 4). In addition, immunoreactivity for thyroid transcription factor-1 (TTF-1), a useful marker for distinguishing primary and metastatic lung tumor [5], was negative (fig. 4c). Thus, diagnosis of metastatic breast cancer was confirmed by the histological and immunohistochemical examination. The patient was treated with trastuzumab ( $2 \mathrm{mg} / \mathrm{kg}$ every week) plus vinorelbine $\left(20 \mathrm{mg} / \mathrm{m}^{2}\right.$ day $1,8,15$, every 4 weeks). No adverse effects, including cardiotoxicity, neurotoxicity or hematotoxicities, have been observed. After 8 courses of chemotherapy, the tracheobronchial wall thickening on chest CT was normalized (fig. 5) and there was an improvement of obstructive air limitation (FEV, $1.90 \mathrm{l}$ and $81.5 \%$ of predicted). The patient has been treated with this regimen and is still alive 16 months after the initiation of chemotherapy.

\section{Discussion}

Among the primary tumors, breast cancer is the most common tumor causing endobronchial metastasis [1-4]. In the present case, tracheobronchial wall thickening and 
edematous mucosa were observed on chest $\mathrm{CT}$ and bronchoscopy, respectively. However, these findings were not specific for suspecting a malignant disease, because there were no lesions suggesting a presence of malignancy. Indeed, it was difficult for us to make a clinical diagnosis before the histological results of biopsy specimens. Thus, we emphasize that diffuse bronchial wall thickening on chest $\mathrm{CT}$ is included as a radiographic manifestation in endobronchial metastasis. Among all the imaging modalities, wholebody PET has a new and unique role in the identification of active status of malignant diseases $[6,7]$. However, FDG-PET also failed to detect the bronchial involvement in the present case. Taken together, the present case highlights the importance of bronchoscopy in the diagnosis of endobronchial metastasis in patients with a history of malignancies.

In the present case, radiographic aspects and the improvement of wall thickening after chemotherapy were observed in the lower trachea and right main bronchus, suggesting main involvement on the right side. As a possible developmental mode of the metastasis in the present case, residual or newly developed malignant cells even after upper lobectomy and subsequent chemotherapy might extend along the bronchus or submucosa invasion. Several studies of endobronchial metastasis indicated that the involved lesions were observed predominantly in right sides [1-3], which was consistent with our case. The reason for this is still unclear and the metastatic route in our case is still speculated on. The involved and developmental pattern in the present case seemed to be a subtype of bronchial invasion by parenchymal lesion proposed by Kiryu et al. [1] and Akoglu et al. [3]. However, our case indicates that serial submucosal invasion along the bronchial wall without intraluminal polypoid growth should be discriminated in metastatic breast cancer.

Bronchoscopic and histological findings may be insufficient to distinguish primary from metastatic tumor on bronchus in some clinical situations [1-3]. In the present case, a history of the underlying diseases and detailed immunohistochemical examination such as HER-2 or TTF-1 was useful to a further appropriate diagnosis and chemotherapeutic strategy. HER-2-positive breast cancer tends to be more aggressive than other types of breast cancer $[8,9]$. The combination of trastuzumab and chemotherapy is significantly superior to chemotherapy alone in terms of both response rates and survival $[8,9]$. The patient was treated with trastuzumab plus vinorelbine, and this resulted in the improvement of tracheobronchial wall thickening and obstructive pulmonary function, suggesting that HER-2 is a useful biological marker for selecting a proper therapy.

In summary, the case presented here suggests that diffuse endobronchial metastasis without grossly visible findings on bronchoscopy could occur in patients with malignancies, especially breast cancer. When radiographic examinations do not reveal intraluminal tumors, lymphadenopathy, or pulmonary metastasis, the possibility of diffuse endobronchial wall spread should be included in the diagnosis and management of patients with breast cancer. 


\begin{tabular}{c|l|l|l}
$\begin{array}{c}\text { Cose Reports in } \\
\text { Oncolady }\end{array}$ & $\begin{array}{l}\text { Case Rep Oncol 2009;2:77-83 } \\
\text { D0I: 10.1159/000215944 }\end{array}$ & Published online: May 9, 2009 & $\begin{array}{l}\text { O 2009 S. Karger AG, Basel } \\
\text { ISSN 1662-6575 } \\
\text { www.karger.com/cro }\end{array}$ \\
\hline
\end{tabular}

Fig. 1. Chest computed tomography demonstrated a tracheobronchial wall thickness before chemotherapy. Arrows indicate the involved lesions.
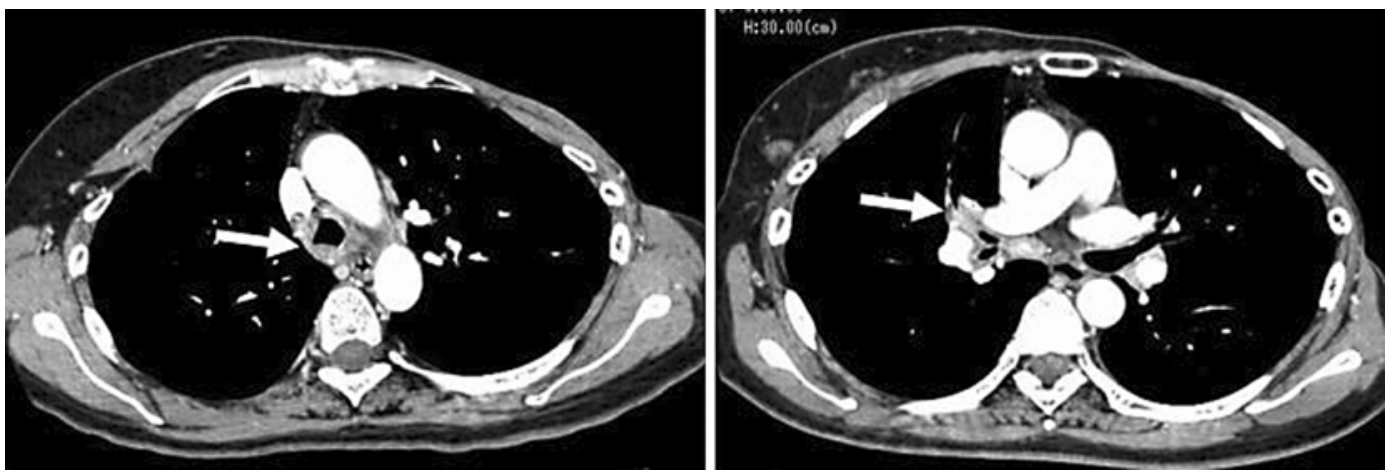

Fig. 2. ${ }^{18}$ F-Fluorodeoxyglucose positron emission tomography scanning before chemotherapy showing no abnormal findings.

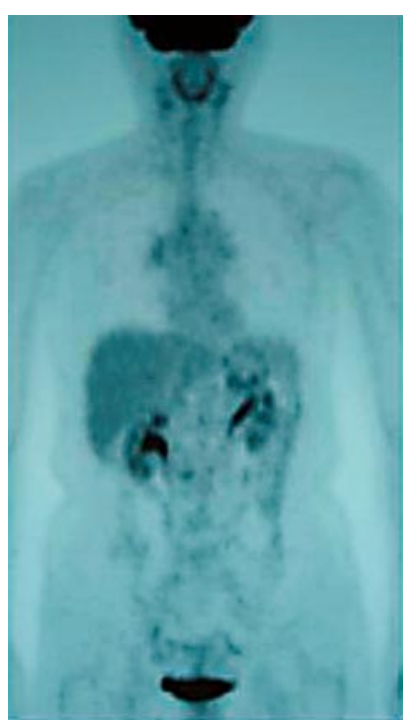




\begin{tabular}{c|l|l|l}
$\begin{array}{c}\text { Cose Reports in } \\
\text { Oncology }\end{array}$ & $\begin{array}{l}\text { Case Rep Oncol 2009;2:77-83 } \\
\text { D01: 10.1159/000215944 }\end{array}$ & Published online: May 9, 2009 & $\begin{array}{l}\text { O 2009 S. Karger AG, Basel } \\
\text { ISSN 1662-6575 } \\
\text { www.karger.com/cro }\end{array}$ \\
\hline
\end{tabular}

Fig. 3. Bronchoscopic findings of carina indicating only edematous mucosa (a) and right spur between middle and basal bronchus showing submucosal edema and mucosal reddish in right bronchi (b).

right main bronchus

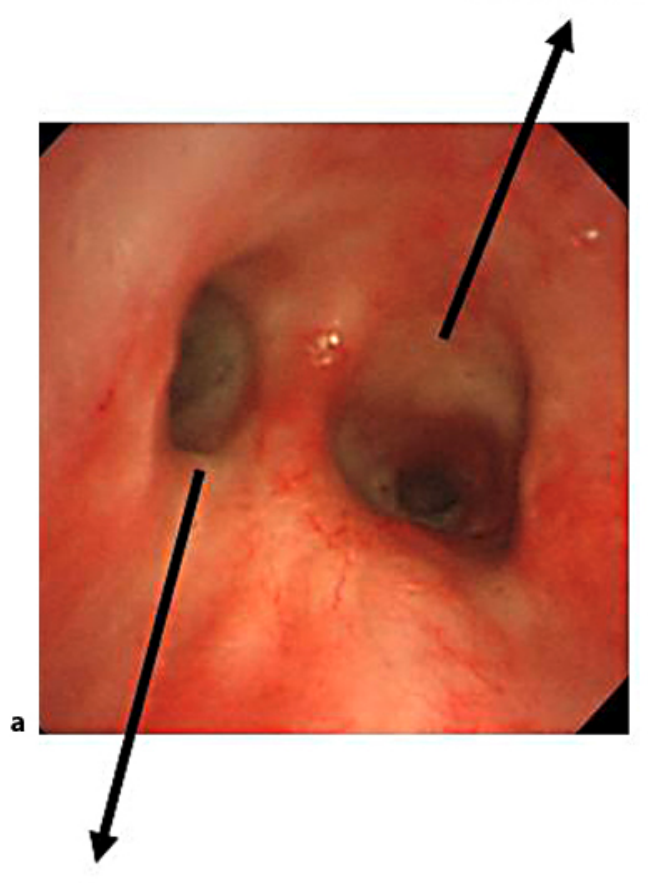

Left main bronchus
Middle bronchus

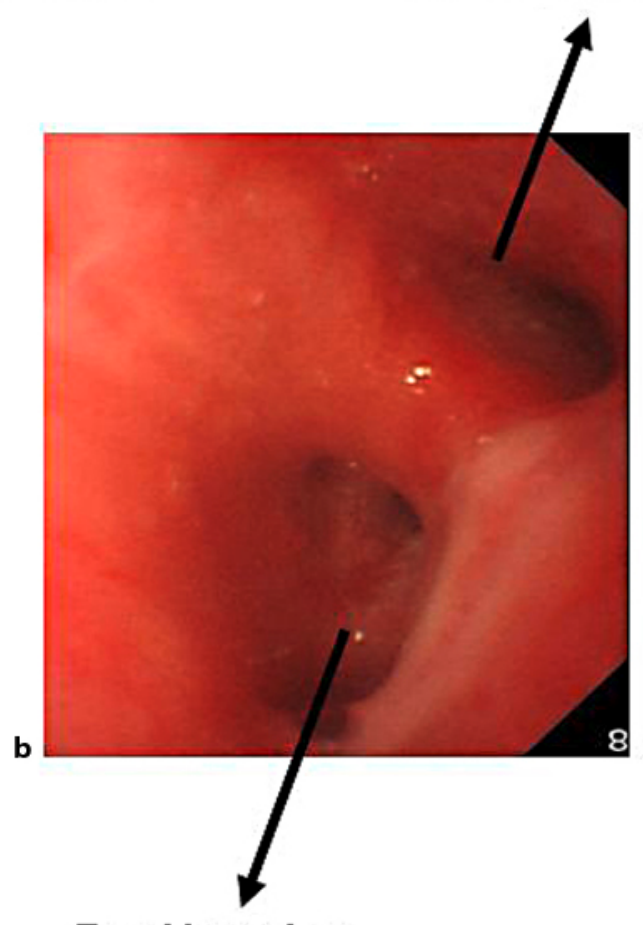

Basal bronchus 


\begin{tabular}{c|l|l|l}
$\begin{array}{c}\text { Cose Reports in } \\
\text { Oncolady }\end{array}$ & $\begin{array}{l}\text { Case Rep Oncol 2009;2:77-83 } \\
\text { D0I: 10.1159/000215944 }\end{array}$ & Published online: May 9, 2009 & $\begin{array}{l}\text { O 2009 S. Karger AG, Basel } \\
\text { ISSN 1662-6575 } \\
\text { www.karger.com/cro }\end{array}$ \\
\hline
\end{tabular}

Fig. 4. Histological findings of bronchial wall specimens showed infiltration of the adenocarcinoma (a). The immunohistological finding was positive for human epidermal growth factor receptor-2 (b) and negative for thyroid tissue factor- 1 (c) $\times 200$.
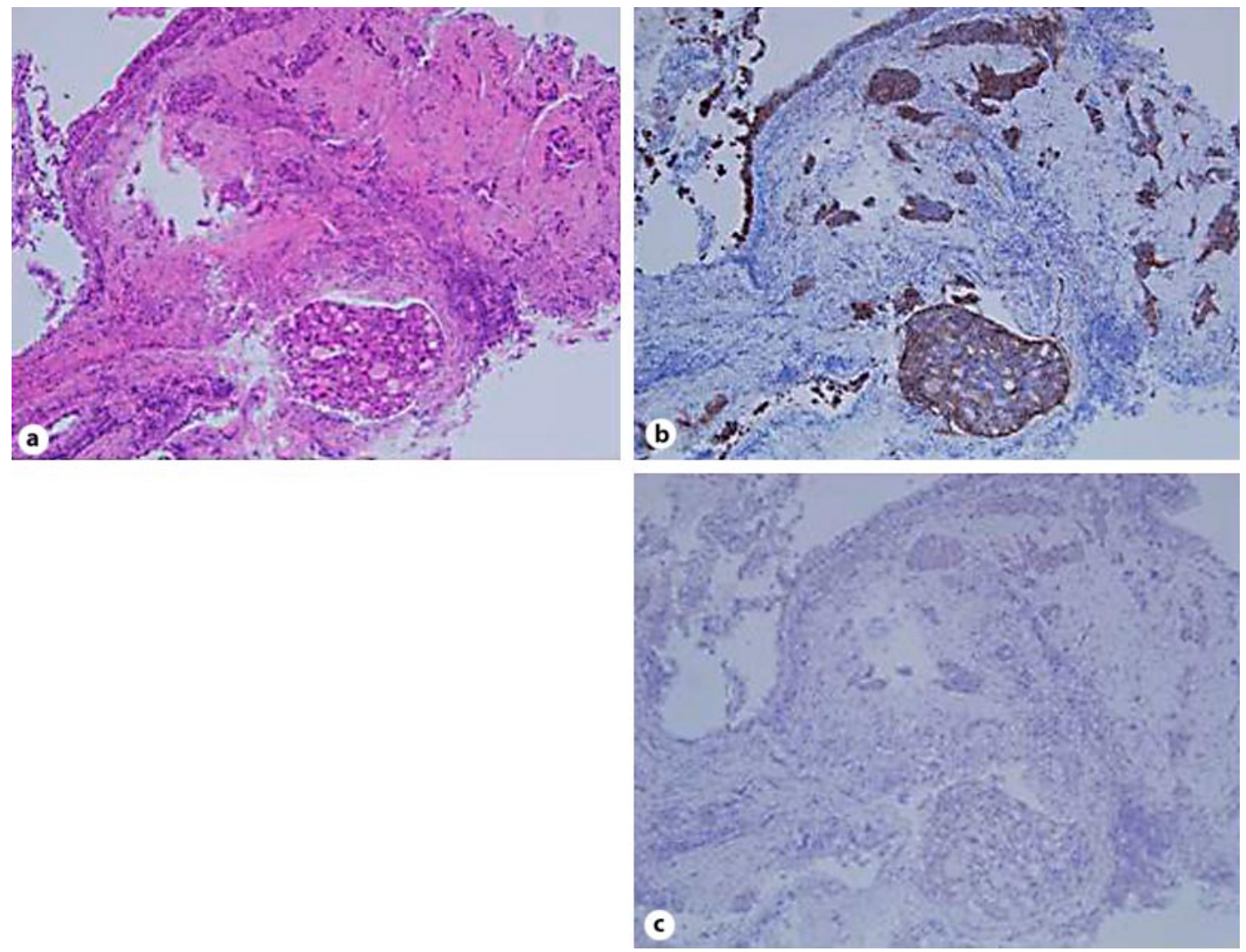

Fig. 5. Chest computed tomography demonstrated improved tracheobronchial wall thickening after chemotherapy.
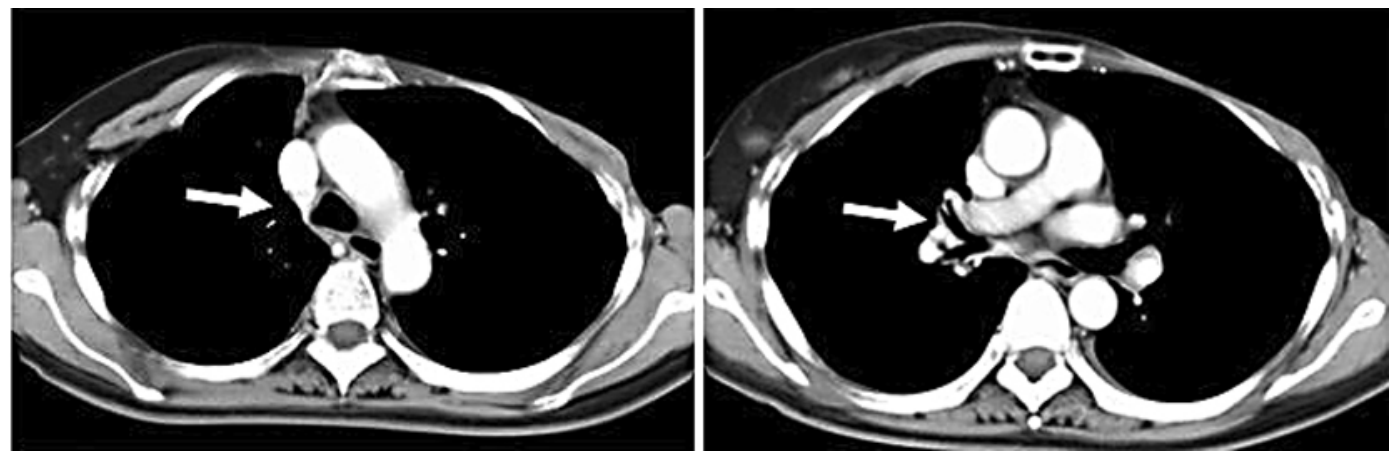


\section{References}

1 Kiryu T, Hoshi H, Matsui E, Iwata H, Kokubo M, Shimokawa K, Kawaguchi S: Endotracheal/endobronchial metastases: clinicopathologic study with special reference to developmental modes. Chest 2001;119:768-775.

2 Salud A, Porcel JM, Rovirosa A, Bellmunt J: Endobronchial metastatic disease: analysis of 32 cases. J Surg Oncol 1996;62:249-252.

3 Akoglu S, Uçan ES, Celik G, Sener G, Sevinç C, Kilinç O, Itil O: Endobronchial metastases from extrathoracic malignancies. Clin Exp Metastasis 2005;22:587591.

4 Jung JI, Kim HH, Park SH, Song SW, Chung MH, Kim HS, Kim KJ, Ahn MI, Seo SB, Hahn ST: Thoracic manifestations of breast cancer and its therapy. Radiographics 2004;24:1269-1285.

5 Bejarano PA, Baughman RP, Biddinger PW, Miller MA, Fenoglio-Preiser C, alKafaji B, Di Lauro R, Whitsett JA: Surfactant proteins and thyroid transcription factor-1 in pulmonary and breast carcinomas. Mod Pathol 1996;9:445-452.

6 Sève P, Billotey C, Broussolle C, Dumontet C, Mackey JR: The role of 2-deoxy-2[F-18] fluoro-D-glucose positron emission tomography in disseminated carcinoma of unknown primary site. Cancer 2007;109:292-299.

7 Lind P, Igerc I, Beyer T, Reinprecht P, Hausegger K: Advantages and limitations of FDG PET in the follow-up of breast cancer. Eur J Nucl Med Mol Imaging 2004;31:S125-S134.

8 Burstein HJ, Keshaviah A, Baron AD, Hart RD, Lambert-Falls R, Marcom PK, Gelman R, Winer EP: Trastuzumab plus vinorelbine or taxane chemotherapy for HER2-overexpressing metastatic breast cancer: the trastuzumab and vinorelbine or taxane study. Cancer 2007;110:965-972.

9 Chan A: A review of the use of trastuzumab (Herceptin) plus vinorelbine in metastatic breast cancer. Ann Oncol 2007;18:1152-1158. 